\title{
A Compact Slotted Patch Hybrid-Mode Antenna for Sub-6 GHz Communication
}

\author{
Bei Huang, ${ }^{1}$ Mochao Li, ${ }^{2}$ Weifeng Lin, ${ }^{2}$ Jun Zhang $\mathbb{D}^{2},{ }^{2}$ Gary Zhang, ${ }^{2}$ and Fugen Wu ${ }^{1}$ \\ ${ }^{1}$ School of Materials and Energy, Guangdong University of Technology, Guangzhou 510006, China \\ ${ }^{2}$ School of Information Engineering, Guangdong University of Technology, Guangzhou 510006, China \\ Correspondence should be addressed to Jun Zhang; junzhang@gdut.edu.cn
}

Received 26 May 2020; Accepted 8 July 2020; Published 31 July 2020

Academic Editor: María Elena de Cos Gómez

Copyright (c) 2020 Bei Huang et al. This is an open access article distributed under the Creative Commons Attribution License, which permits unrestricted use, distribution, and reproduction in any medium, provided the original work is properly cited.

A compact hybrid-mode antenna is proposed for sub- $6 \mathrm{GHz}$ communication. The proposed antenna is composed of a slotted rectangular patch, a feeding dipole, and a balun. Three modes are sequentially excited in a shared patch to achieve a compact size. A prototype antenna with a major size of $0.48 \lambda_{0} \times 0.31 \lambda_{0} \times 0.16 \lambda_{0}\left(\lambda_{0}\right.$ is the wavelength in the free space at the center of the operating frequency band) is fabricated and measured. The measured results demonstrate an impedance bandwidth of $56.87 \%$ from $2.97 \mathrm{GHz}$ to $5.33 \mathrm{GHz}$ and an average gain of approximately $8.00 \mathrm{dBi}$ with $1 \mathrm{~dB}$ variation in the operating frequency band of 3.0-5.0 GHz. The proposed antenna can be an element for microbase stations in sub-6 GHz communication.

\section{Introduction}

With the rapid development of wireless communication systems, the demands for high-speed and low-latency data services have increased exponentially. Fifth-generation (5G) communication enables higher coverage and a larger capacity to support new deployment scenarios such as 3D video, ultrahigh-definition screens, and industry automation [1]. To standardize $5 \mathrm{G}$ implementation for new radio (NR) development, the 3GPP divided bands into low, mid, and high frequencies. Midband frequencies, from $2 \mathrm{GHz}$ to $24 \mathrm{GHz}$, are conducive to supporting coverage, capacity, mobility, and high data rates through the larger 5G bandwidth channels [2]. Therefore, microbase stations need to be densely deployed for ubiquitous access. To meet the requirements, the antenna element needs to be of low cost, light weight, and broadband and needs to have high gain, a stable radiation pattern, low cross polarization, large frontto-back ratio, and small gain variation over the whole operating frequency band. For example, an indoor femtocell is required for high data rate service for a small number of users as a hot spot.

For a simple narrowband system with a single resonance, the impedance bandwidth can be accurately estimated by its quality $Q$-factor via an inverse proportionality relation [3]. In the case of a dipole array above a ground plane, more than half of the energy is stored between the radiator and the ground plane [4]; therefore, the impedance bandwidth is directly proportional to the antenna profile. Increasing the thickness of the substrate is beneficial for broadening the impedance bandwidth of the antenna, but a thick substrate may increase loss because of the excitation of the surface wave. Fortunately, the antenna bandwidth is not limited by its $Q$-factor when the antenna has multiple resonances [5]. The superposition of just two modes allows multiple resonances and wideband response if the modes are properly combined [6].

A magnetic-electric (ME) dipole is considered to enhance the bandwidth and smooth the radiation pattern by combining two orthogonally placed complementary dipoles, i.e., an electric dipole and a magnetic dipole. The former can be treated as a series resonance, while the latter is represented as a parallel resonance [7]. Shared-aperture technology is desired to make patch antennas compact and light [8]. Through mode hybridization, adjacent modes were sequentially excited in the band of interest $[9,10]$. These hybrid-mode antennas have the merits of low profile, broad bandwidth, and stable radiation pattern, but the structures are complicated and costly. 
The slotting technique is a way to change the field distribution of a conventional patch antenna, which leads to bandwidth enhancement. Through the control of the dimensions of the strips and the slots, dual modes, i.e., the $\mathrm{TM}_{10}$ mode and antiphase $\mathrm{TM}_{20}$ mode, were excited and coupled to increase the operating bandwidth [11]. Fed by an L-shaped probe, the conventional patch with a U-shaped slot introduced a capacitance in parallel with the probe to create an additional resonance [12]. With a profile of $0.25 \lambda_{0}\left(\lambda_{0}\right.$ is the wavelength in the free space at the center of the operating frequency band), a differentially driven $\mathrm{H}$-slot patch with an L-plate feeding method could generate a third resonance with a wide impedance bandwidth of $115 \%$ [13]. Moreover, a differentially driven microstrip patch antenna with a bandwidth of approximately $55 \%$ and a profile of $0.06 \lambda_{0}$ was proposed by incorporating a resonant mode of the slot into the $\mathrm{TM}_{10}$ and $\mathrm{TM}_{12}$ modes of the patch resonator [14].

This paper is an extension of a conference paper [15], wherein the three modes of the patch/dipole/slot are sequentially excited and shared in one radiator to achieve a compact size. A proper balun [16] is designed differentially to excite the feeding dipole and provide more flexibility for impedance matching in the band of interest. Similar to [17], the proposed antenna aims to reduce the complexity and cost of the hybrid-mode antennas [9, 10]. In addition to suppressing the spurious radiation from the balun such as in [17], here, a slot mode is excited in the band of interest to improve the radiation stability. The remainder of this paper is organized as follows. The configuration and operation of the proposed hybrid-mode antenna are described and analyzed in Section 2. Section 3 presents the simulated and measured results. Finally, conclusions are drawn in Section 4.

\section{Antenna Design and Analysis}

2.1. Antenna Structure. The geometry of the proposed hybrid-mode antenna is presented in Figure 1. The antenna is composed of three substrates. A slotted rectangular patch is printed on the lower side of the top substrate, which is used to enhance the impedance bandwidth. The fundamental mode of the slot can be excited by increasing the length of the slot. Similar to the inverted microstrip line feed for a cavity-backed slot antenna [18], an inverted feeding dipole is placed on the upper side of the top substrate to excite the patch as well as to ease the assembly. Radiation is emitted at the end of the dipole. Here, the slot and dipole share the same radiator with the patch to achieve a compact size.

An integrated balun is sandwiched between the top and bottom substrates, which can excite the balanced mode by making use of the coupling between the microstrip line printed on one side of the substrate and the slot etched on the other side of the substrate [16]. Similarly, the broadband balun can transform the impedance and match the $50 \Omega$ single-ended feed by adjusting the balun slot [19]. The balun profile can provide an additional resonance for broadening the matching bandwidth.

The three substrates are low-cost FR4 materials with a relative permittivity of 4.40 and a loss tangent of 0.02 . The size of the top substrate is $50 \mathrm{~mm} \times 50 \mathrm{~mm}$ and that of the bottom substrate is $100 \mathrm{~mm} \times 100 \mathrm{~mm}$. The thickness of the top and bottom substrates is $1.60 \mathrm{~mm}$, while the thickness of the substrate of the balun is $0.40 \mathrm{~mm}$. The other dimensions of the proposed antenna are detailed in Table 1. It is noted that there are four nonplated through holes (NPTHs) in the top substrate as well as the bottom substrate for assembly. There are eight plating through holes (PTHs) in the bottom substrate to ease the soldering of the two ground planes of the balun and antenna.

2.2. Operating Principle. Through proper integration of the slotted patch, dipole, and balun, five resonances can be excited. A parametric study is conducted in Figure 2. Since the two resonances from the balun slot and balun profile do not participate in radiation, they are placed as the first and fifth modes, respectively. Because the dipole is placed near the slotted patch, the radiation is low due to the effect of the nearby conductor [20]. The dipole mode is, therefore, placed in the third resonance to achieve a stable gain in the band of interest. An increase in the slot length shifts the resonance of the patch mode to a lower frequency region. Hence, the resonance of the patch is placed as the second mode, and the slot mode is placed in the fourth resonance. To achieve a stable gain variation, the higher-order mode of the patch should be removed from the band of interest. Therefore, the second, third, and fourth resonances are mainly determined by the patch, dipole, and slot, respectively. The first and fifth resonances are dominated by the balun slot and balun profile, respectively.

The evolution of the proposed antenna in terms of $\left|S_{11}\right|$ is studied in Figure 3. To demonstrate the radiation modes of the proposed antenna, we examine the electric field distributions near the major radiator, which are shown in Figure 4. At $3.0 \mathrm{GHz}$, the electric field is mainly concentrated near the patch. The electric field appears near the two ends of the dipole at $3.6 \mathrm{GHz}$. The electric field can be observed on the slot at $4.8 \mathrm{GHz}$. Therefore, it is obvious that among the operating frequency bands, the lower frequency is determined by the patch mode, the middle frequency is governed by the dipole mode, and the higher frequency is dominated by the slot mode. Additionally, the polarization is maintained for the three modes ( $y$-polarized), and stable radiation patterns can be anticipated as well.

\section{Results and Discussion}

A prototype of the proposed hybrid-mode antenna was fabricated and tested. The photograph is shown in Figure 5. Nylon screws are used to support the frame.

Figure 6 illustrates the simulated and measured reflection coefficients and peak realized gains versus frequency. The operating frequency band of this antenna covers 3.0 to $5.0 \mathrm{GHz}$ with a center frequency of $4.0 \mathrm{GHz}$. The simulated $10-\mathrm{dB}$ impedance bandwidth is $53.79 \%$, covering $2.99 \mathrm{GHz}$ to $5.19 \mathrm{GHz}$, whereas the measured value is $56.87 \%$, ranging from $2.97 \mathrm{GHz}$ to $5.33 \mathrm{GHz}$. The simulated peak realized gain is $8.60 \pm 0.47 \mathrm{dBi}$, whereas the measured gain is $8.00 \pm 0.50 \mathrm{dBi}$. The slight discrepancy between the simulated and measured gains is mainly due to the increased loss in the substrate material.

For the simulated radiation efficiency in the operating band, the maximum value is $90.00 \%$ at $4.6 \mathrm{GHz}$, while the minimum value is $78.10 \%$ at $3.0 \mathrm{GHz}$. The radiation patterns 


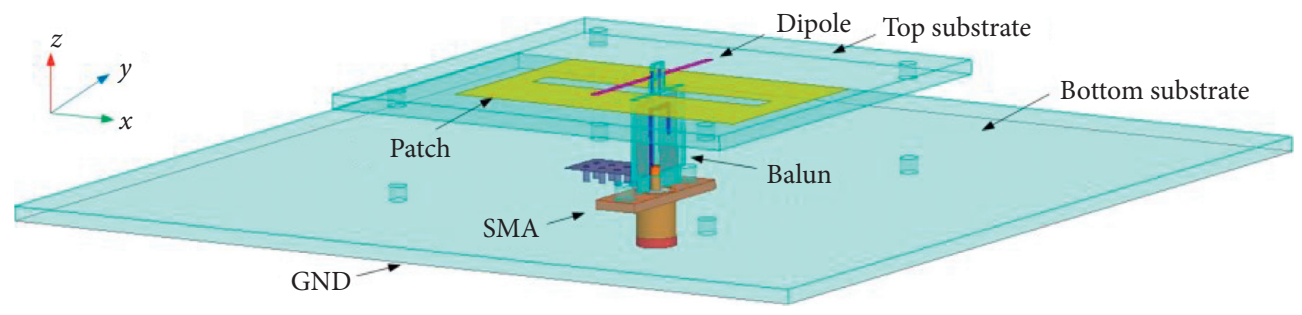

(a)

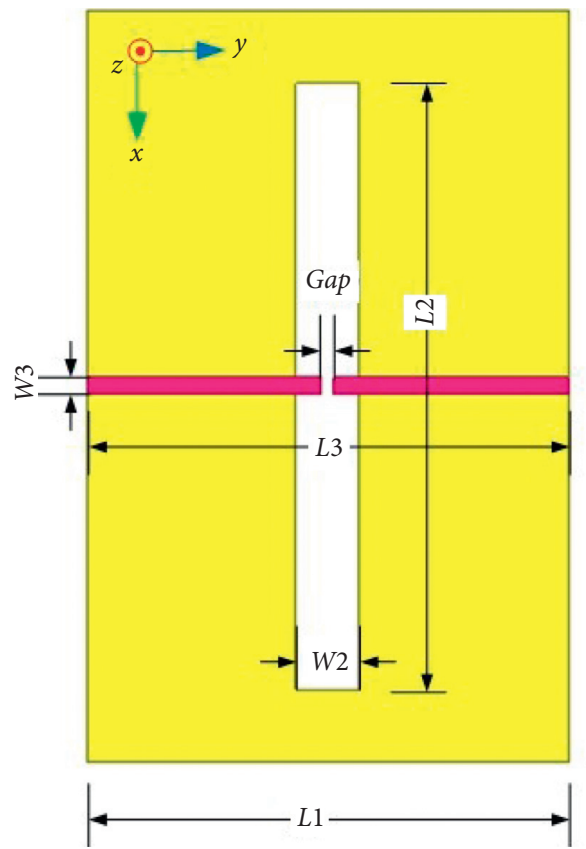

(b)

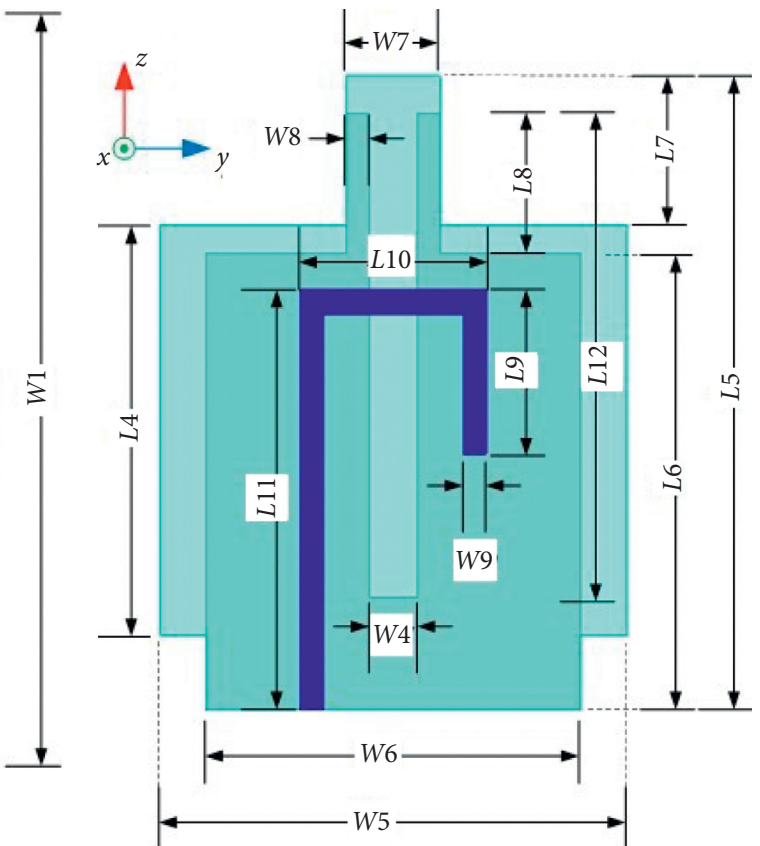

(c)

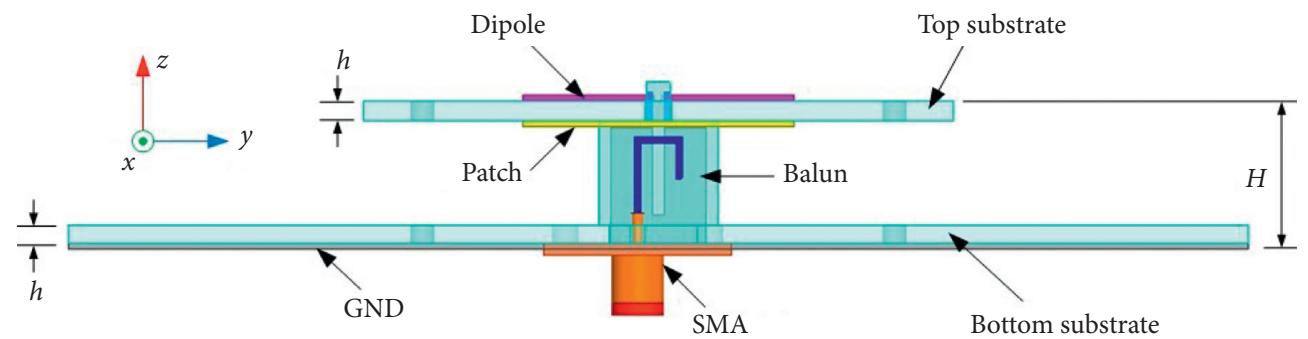

(d)

FIGURE 1: Geometry of the proposed antenna: (a) perspective view, (b) the radiator, (c) the balun structure, and (d) side view.

TABLE 1: Dimensions of the proposed antenna.

\begin{tabular}{lccccc}
\hline Parameter & Value $(\mathrm{mm})$ & Parameter & Value $(\mathrm{mm})$ & Parameter & Value $(\mathrm{mm})$ \\
\hline$L_{1}$ & 23.0 & $L_{2}$ & 29.0 & $L_{3}$ & 23.0 \\
$L_{4}$ & 8.8 & $L_{5}$ & 13.6 & $L_{6}$ & 9.8 \\
$L_{7}$ & 3.8 & $L_{8}$ & 3.0 & $L_{9}$ & 3.5 \\
$L_{10}$ & 4.0 & $L_{11}$ & 9.0 & $L_{12}$ & 10.4 \\
$W_{1}$ & 36.0 & $W_{2}$ & 3.0 & $W_{3}$ & 0.8 \\
$W_{4}$ & 1.0 & $W_{5}$ & 10.0 & $W_{6}$ & 8.0 \\
$W_{7}$ & 2.0 & $W_{8}$ & 0.5 & $W_{9}$ & 0.5 \\
Gap & 0.6 & $h$ & 1.6 & $H$ & 12.0 \\
\hline
\end{tabular}



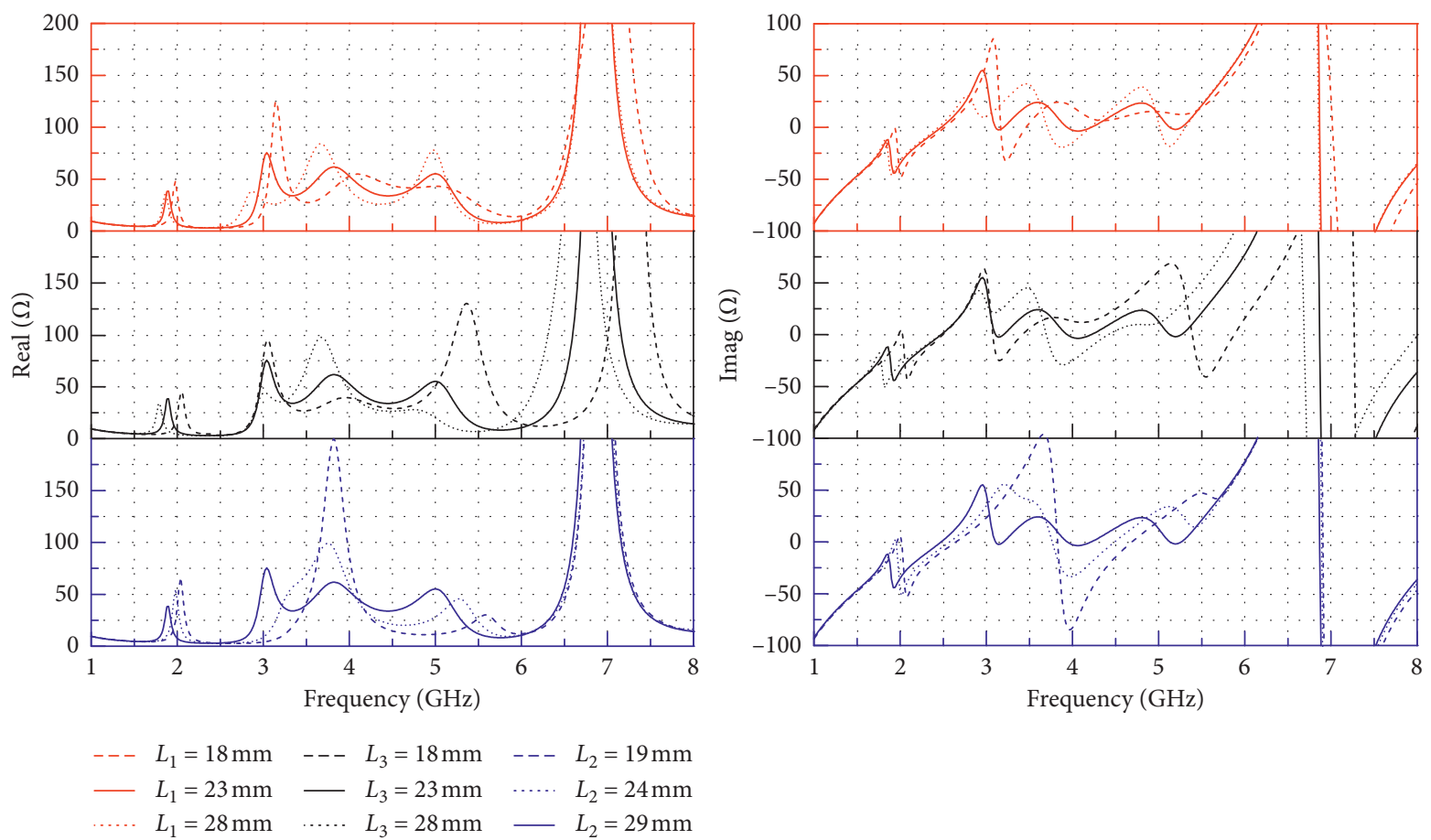

$$
\begin{aligned}
& \text { - - } L_{1}=18 \mathrm{~mm}---L_{3}=18 \mathrm{~mm} \quad--L_{2}=19 \mathrm{~mm} \\
& \cdots L_{1}=28 \mathrm{~mm} \quad \cdots \cdots L_{3}=28 \mathrm{~mm} \quad \longrightarrow \quad L_{2}=29 \mathrm{~mm}
\end{aligned}
$$

(a)
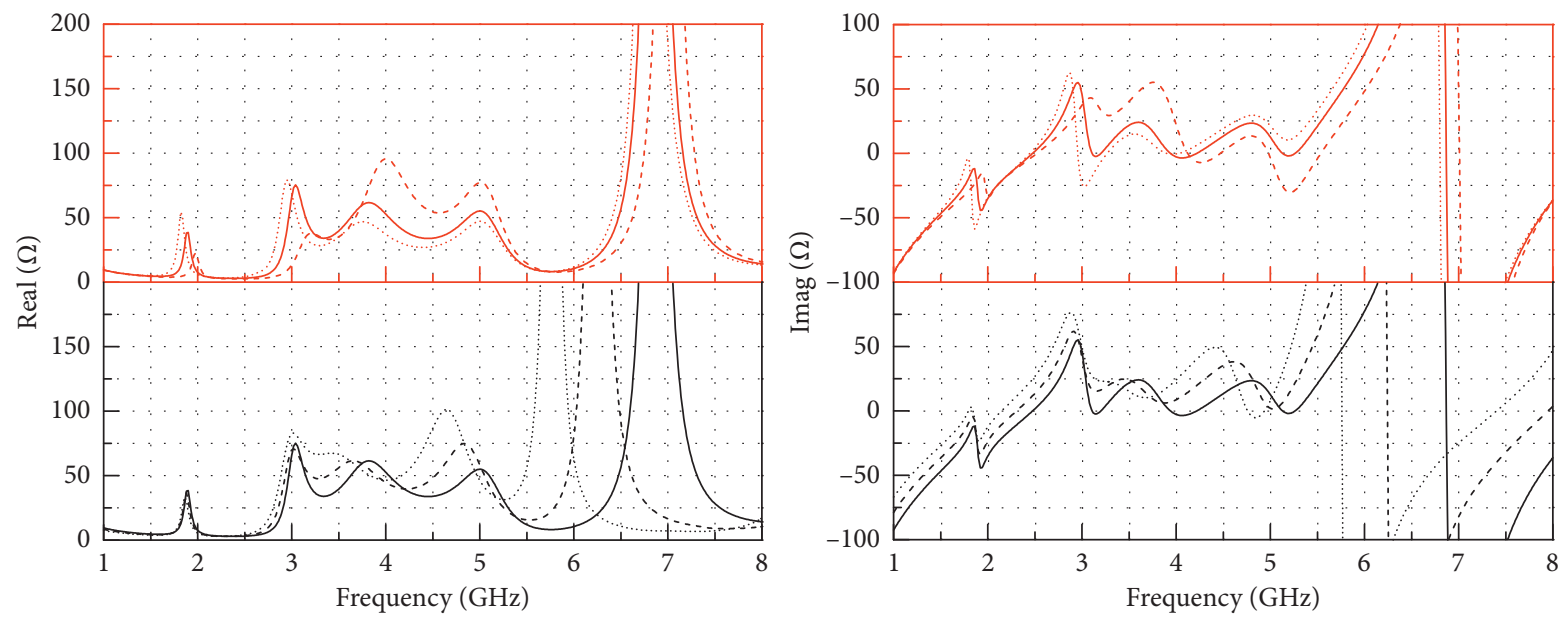

$$
\begin{aligned}
& --L_{12}=8.4 \mathrm{~mm} \quad-L_{4}=8.8 \mathrm{~mm} \\
& -L_{12}=10.4 \mathrm{~mm} \quad---L_{4}=10.8 \mathrm{~mm} \\
& \text { … } L_{12}=12.4 \mathrm{~mm} \quad \ldots \ldots . . L_{4}=12.8 \mathrm{~mm}
\end{aligned}
$$

(b)

Figure 2: Parametric study of the input impedance (real part in the left column and imaginary part in the right column): (a) the effects of the patch length $\left(L_{1}\right)$, dipole length $\left(L_{3}\right)$, and slot length $\left(L_{2}\right)$ and (b) the effects of the balun slot $\left(L_{12}\right)$ and balun profile $\left(L_{4}\right)$.

of the proposed hybrid-mode antenna are displayed in Figure 7. In general, the proposed antenna can maintain stable radiation patterns over the operating frequency band. The simulated half-power beam widths (HPBWs) at 3.0 $\mathrm{GHz}, 3.6 \mathrm{GHz}$, and $4.8 \mathrm{GHz}$ are $60.58^{\circ}, 63.46^{\circ}$, and $66.92^{\circ}$ in the $x o z$-plane and $67.12^{\circ}, 71.96^{\circ}$, and $69.03^{\circ}$ in the yozplane, respectively. The measured values are $64.08^{\circ}, 61.84^{\circ}$, and $67.07^{\circ}$ in the $x o z$-plane and $68.36^{\circ}, 67.62^{\circ}$, and $71.50^{\circ}$ in the yoz-plane, respectively. The simulated crosspolarizations are $-26.93 \mathrm{~dB},-32.09 \mathrm{~dB}$, and $-30.85 \mathrm{~dB}$ at $3.0 \mathrm{GHz}$, $3.6 \mathrm{GHz}$, and $4.8 \mathrm{GHz}$, whereas the measured values are $-22.00 \mathrm{~dB},-20.89 \mathrm{~dB}$, and $-20.06 \mathrm{~dB}$, respectively. The discrepancy between the simulated and measured crosspolarization can be attributed to assembly and measurement errors.

A comparison between the proposed antenna and previous bandwidth enhanced antennas is presented in Table 2. Although the profile is higher than that in $[11,14]$, 


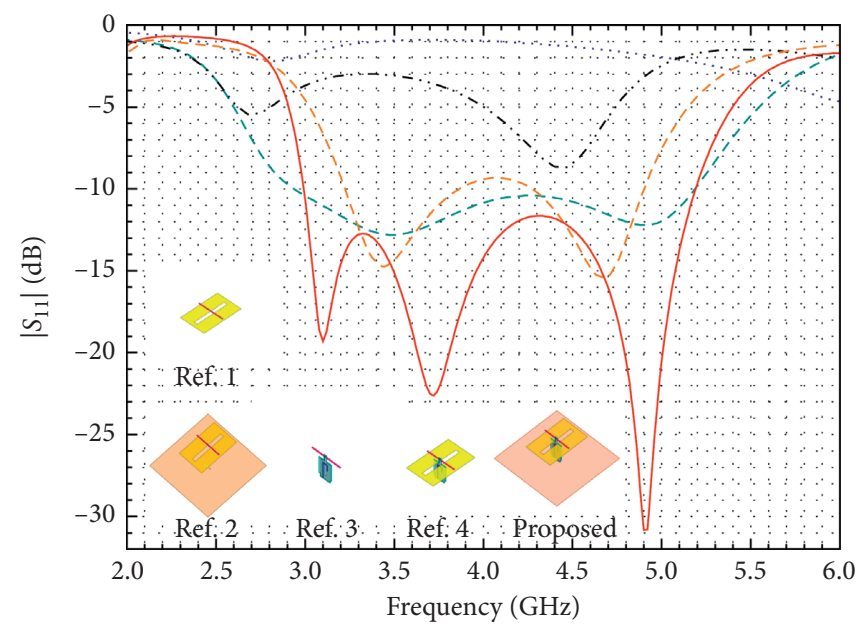

$$
\begin{array}{ll}
\ldots \text { Ref. } 1 & \text {-- } \\
\ldots \text { Ref. } 4 \\
--- \text { Ref. } 2 \\
\text {-... } & \text { Ref. } 3
\end{array}
$$

FigURE 3: Evolution of the proposed antenna.

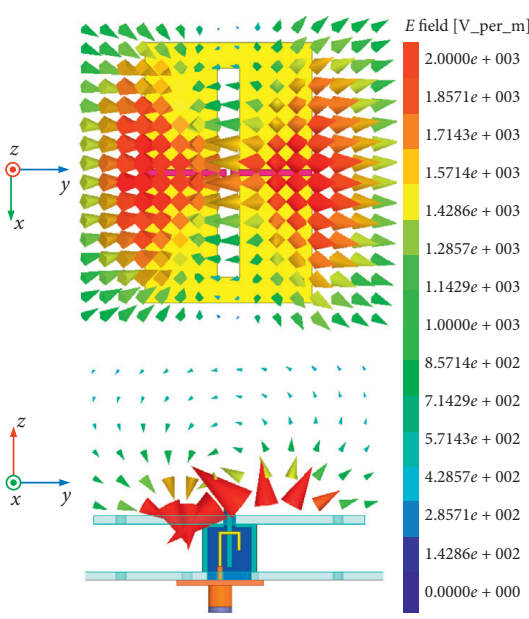

(a)

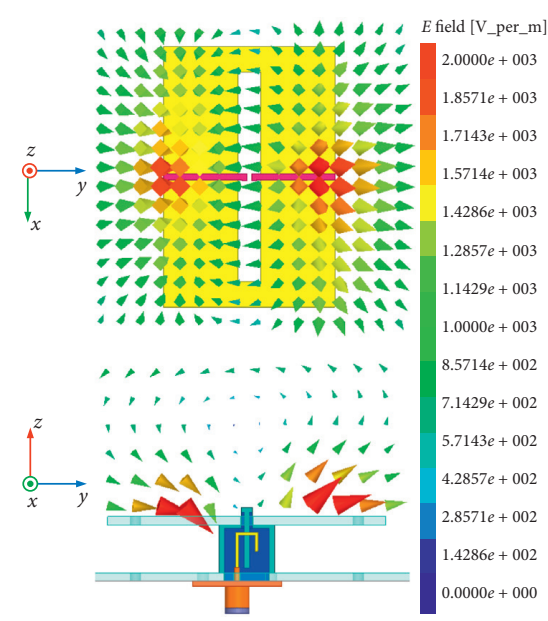

(b)

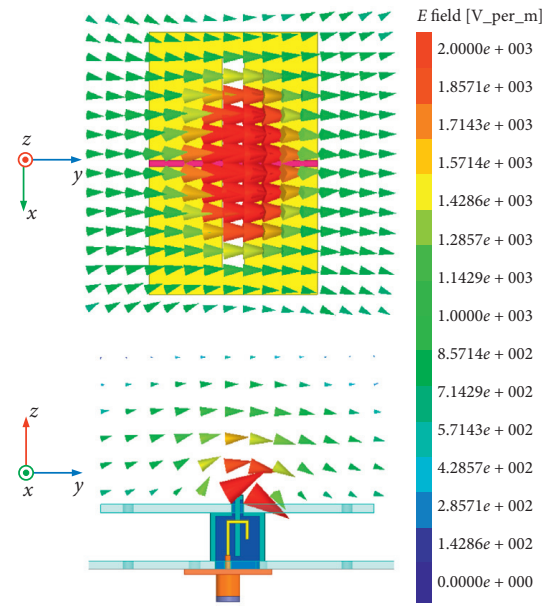

(c)

FIGURE 4: Electric field distributions of the proposed antenna: (a) $3.0 \mathrm{GHz}$, (b) $3.6 \mathrm{GHz}$, and (c) $4.8 \mathrm{GHz}$.

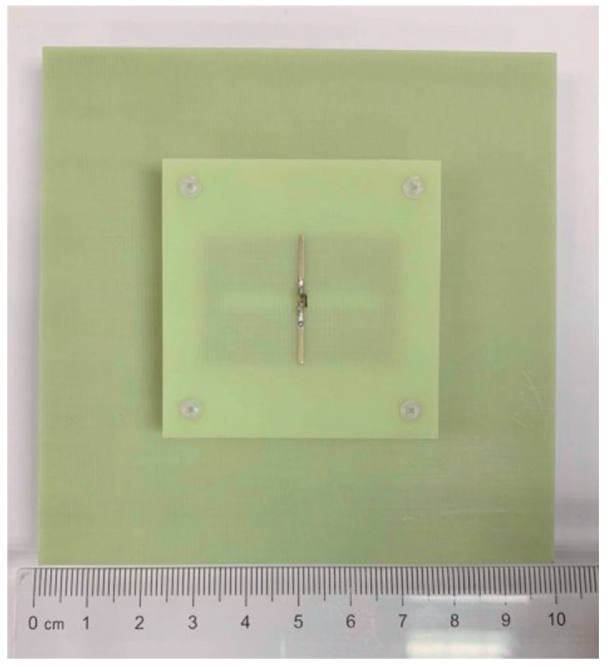

(a)

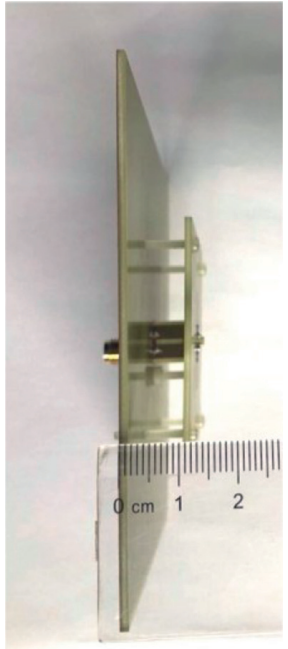

(b)

Figure 5: Photograph of the antenna prototype: (a) top view and (b) side view. 


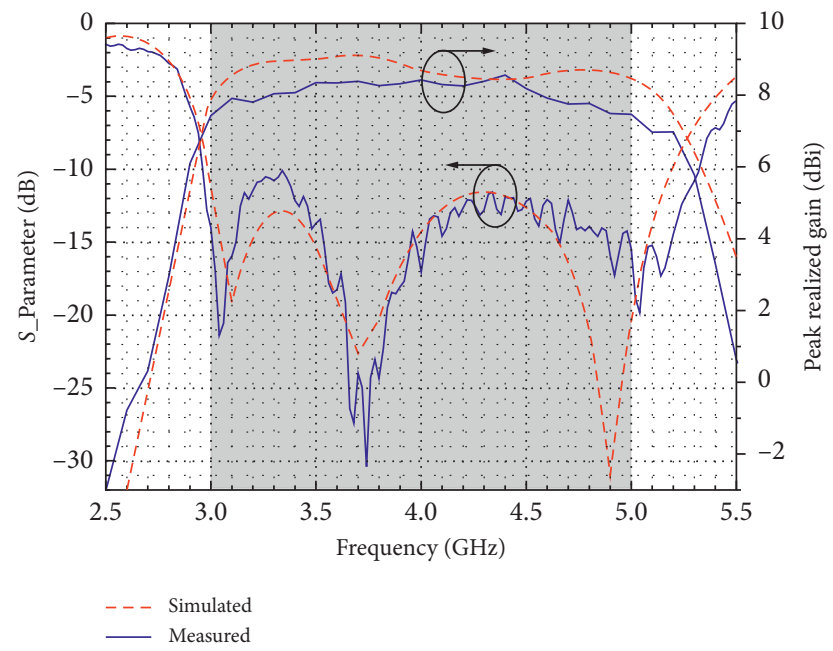

Figure 6: The simulated and measured reflection coefficients and peak realized gains of the proposed antenna.
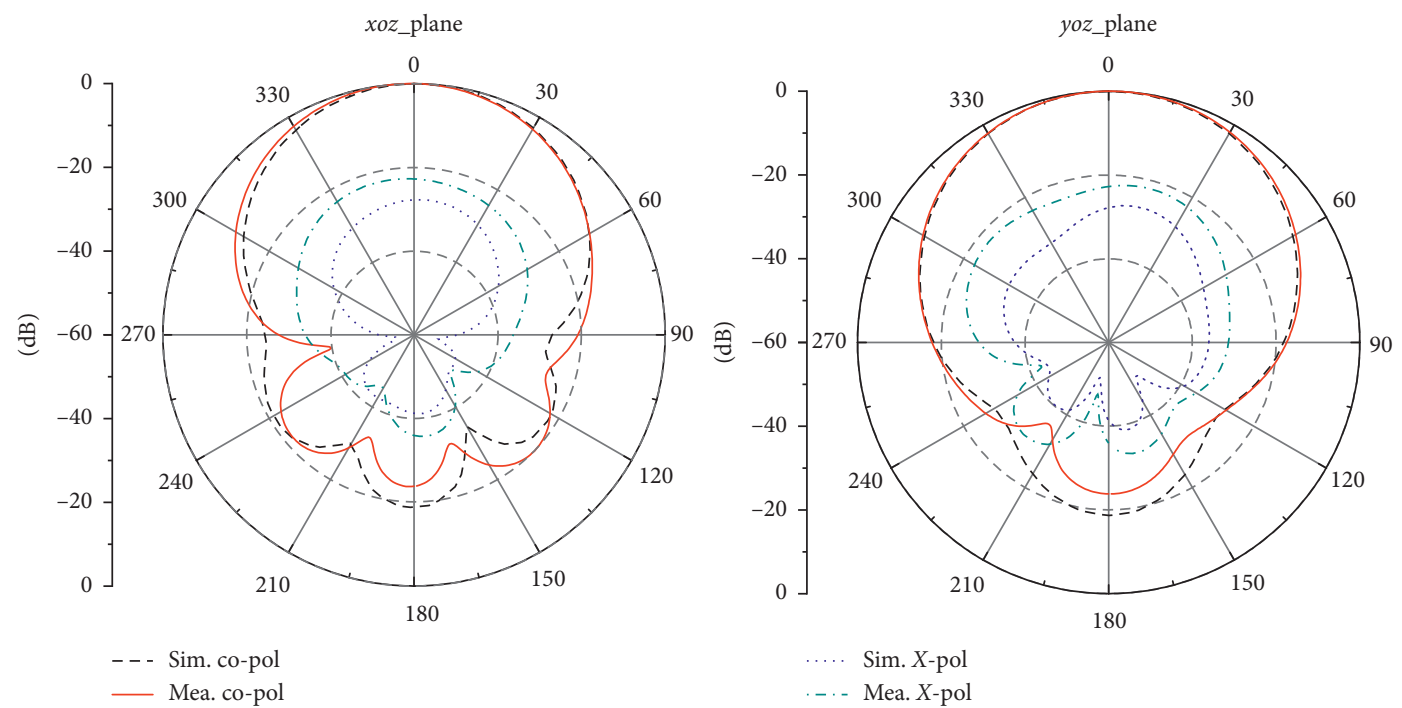

(a)
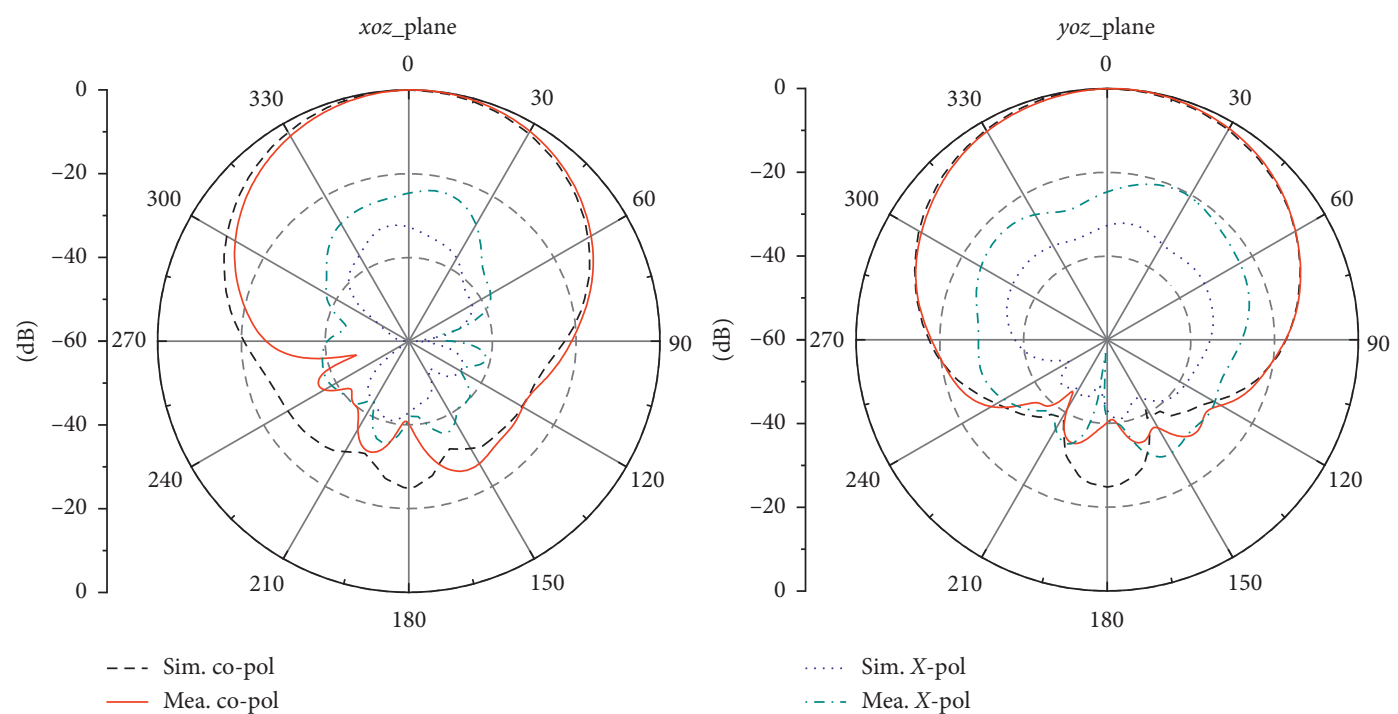

(b)

Figure 7: Continued. 


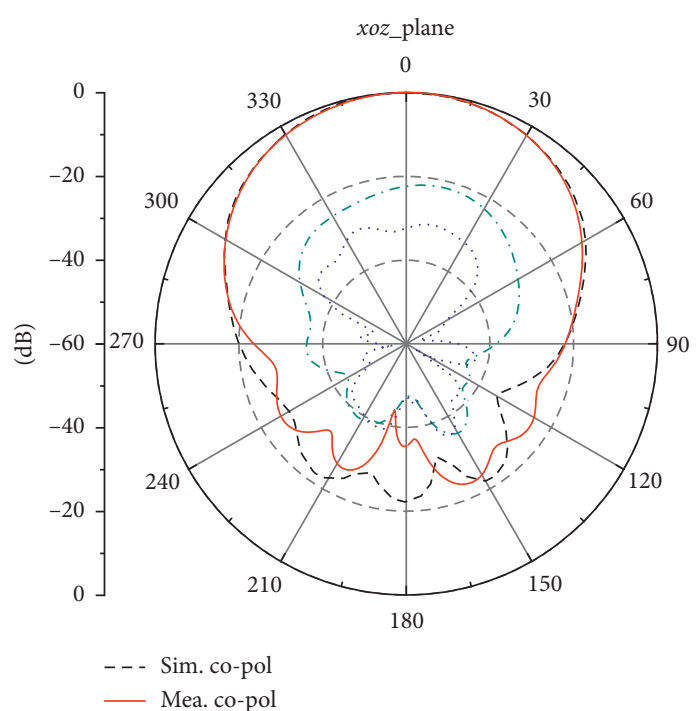

(c)

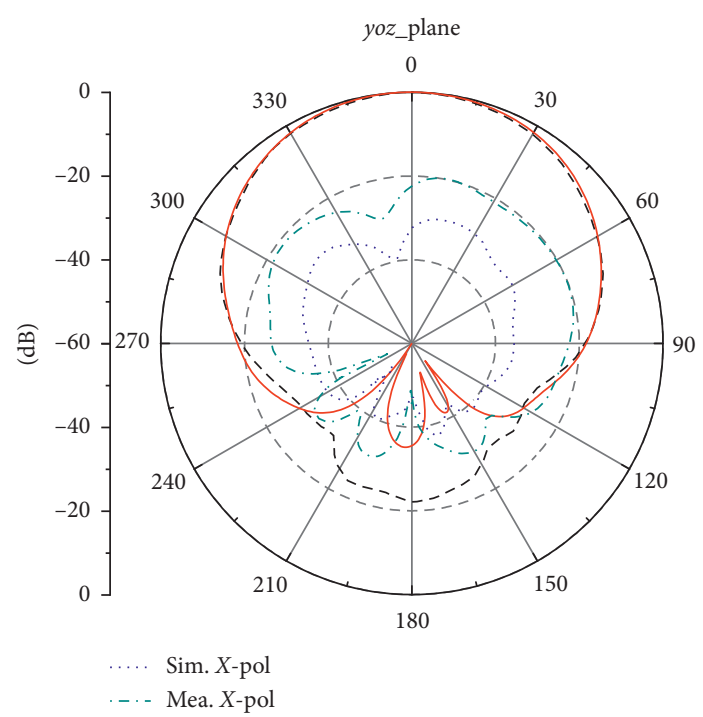

... Mea. $X$-pol

FIGURE 7: Simulated and measured radiation patterns of the proposed antenna: (a) $3.0 \mathrm{GHz}$, (b) $3.6 \mathrm{GHz}$, and (c) $4.8 \mathrm{GHz}$.

TABLe 2: Comparison with bandwidth enhanced antennas.

\begin{tabular}{|c|c|c|c|c|c|c|c|}
\hline \multirow{2}{*}{ Ref. } & \multirow{2}{*}{$\begin{array}{l}\text { Size of major radiator } \\
\qquad\left(\lambda_{0} \times \lambda_{0} \times \lambda_{0}\right)\end{array}$} & \multirow{2}{*}{$\begin{array}{l}\text { Bandwidth } \\
\text { (\%) }\end{array}$} & \multirow{2}{*}{$\begin{array}{l}\text { Realized gain } \\
\qquad(\mathrm{dBi})\end{array}$} & \multirow{2}{*}{ Crosspolarization } & \multirow{2}{*}{$\begin{array}{l}\text { Front-to-back ratio } \\
\qquad(\mathrm{dB})\end{array}$} & \multicolumn{2}{|c|}{ HPBW $\left({ }^{\circ}\right)^{\#}$} \\
\hline & & & & & & $x o z$ & yoz \\
\hline [14] & $1.04 \times 0.81 \times 0.06$ & 55.00 & $7.50 \pm 2.50$ & -19.20 & 12.50 & 46.34 & 59.46 \\
\hline [17] & $0.90 \times 0.78 \times 0.13$ & 67.50 & $8.40 \pm 1.10$ & -28.50 & 36.50 & 55.70 & 43.30 \\
\hline [21] & $0.45 \times 0.45 \times 0.24$ & 57.78 & $8.20 \pm 0.80$ & -20.00 & 30.00 & 62.50 & 61.80 \\
\hline$[22]$ & $1.12 \times 0.40 \times 0.03$ & 15.20 & $4.90 \pm 1.90$ & -18.00 & 13.20 & $\mathrm{~N} / \mathrm{A}$ & $\mathrm{N} / \mathrm{A}$ \\
\hline $\begin{array}{l}\text { This } \\
\text { work* }\end{array}$ & $0.48 \times 0.31 \times 0.16$ & 56.87 & $8.00 \pm 0.50$ & -20.48 & 24.24 & 60.23 & 66.31 \\
\hline
\end{tabular}

\#the values of the HPBWs are at the center of the operating frequency band; * the radiation performance is extracted from the operating frequency band of 3.0-5.0 GHz.

the proposed antenna has more stable radiation patterns for steady coverage. Compared with [17], the radiation stability in terms of gain and pattern is improved by the proper balun design and an additional resonance provided in the band of interest. Moreover, the projection area is reduced from $0.90 \lambda_{0} \times 0.78 \lambda_{0}$ to $0.48 \lambda_{0} \times 0.31 \lambda_{0}$. The performance of the proposed antenna is competitive with [21], but the profile in [21] is high. The profile in [22] is very low, but it is a sacrifice of the bandwidth and the realized gain.

\section{Conclusions}

In this paper, a compact slotted patch fed by a dipole is designed to sequentially excite the patch mode, dipole mode, and slot mode in the band of interest. Measurements from the antenna prototype demonstrate that the proposed antenna features an impedance bandwidth of $56.87 \%$ in a compact size. An average antenna gain of $8.00 \mathrm{dBi}$ with $1 \mathrm{~dB}$ variation is achieved while the HPBWs are maintained over the operating band of 3.0 to $5.0 \mathrm{GHz}$. The shape variation together with the balun design is beneficial for antenna size reduction. The single polarization antenna can be a part of a dual-polarized subarray for macrobase stations, where the alternating polarization scheme may yield higher throughput gains [23]. The proposed compact antenna may demonstrate competitive performance for linearly polarized sub$6 \mathrm{GHz}$ base station applications, either for ubiquitous access in rural areas or indoor femtocell scenarios.

\section{Data Availability}

The data used to support the findings of this study are included within the article.

\section{Conflicts of Interest}

The authors declare that there are no conflicts of interest regarding the publication of this paper.

\section{Acknowledgments}

This work was supported in part by the National Key Research and Development Program of China (no. 2018YFB1802100), in part by the National Natural Science Foundation of China (nos. 61701120 and 61974035), and in part by the Guangdong Provincial Key Project of Science and Technology (no. 2018B010115001). 


\section{References}

[1] Y. Yifei and Z. Longming, "Application scenarios and enabling technologies of 5G," China Communications, vol. 11, no. 11, pp. 69-79, 2014.

[2] 5G Americas, 5G Americas White Paper, 5G Americas, Bellevue, WA, USA, 2019, https://www.5gamericas.org/ advanced-antenna-systems-for- $5 \mathrm{~g} /$.

[3] M. Gustafsson and B. L. G. Jonsson, "Antenna $Q$ and stored energy expressed in the fields, currents, and input impedance," IEEE Transactions on Antennas and Propagation, vol. 63, no. 1, pp. 240-249, 2015.

[4] D.-H. Kwon and D. M. Pozar, "Energy storage and radiation \$Q\$ of infinite planar dipole phased arrays," IEEE Transactions on Antennas and Propagation, vol. 62, no. 1, pp. 153-162, 2014.

[5] D. F. Sievenpiper, D. C. Dawson, M. M. Jacob et al., "Experimental validation of performance limits and design guidelines for small antennas," IEEE Transactions on Antennas and Propagation, vol. 60, no. 1, pp. 8-19, 2012.

[6] J. J. Adams and J. T. Bernhard, "A modal approach to tuning and bandwidth enhancement of an electrically small antenna," IEEE Transactions on Antennas and Propagation, vol. 59, no. 4, pp. 1085-1092, 2011.

[7] K.-M. Luk and B. Wu, "The magnetoelectric dipole-a wideband antenna for base stations in mobile communications," Proceedings of the IEEE, vol. 100, no. 7, pp. 2297-2307, 2012.

[8] D. M. Pozar and S. D. Targonski, "A shared-aperture dualband dual-polarized microstrip array," IEEE Transactions on Antennas and Propagation, vol. 49, no. 2, pp. 150-157, 2001.

[9] J. Zhang and Z. Shen, "Compact and high-gain UHF/UWB RFID reader antenna," IEEE Transactions on Antennas and Propagation, vol. 65, no. 10, pp. 5002-5010, 2017.

[10] J. Zhang and Z. Shen, "Dual-band shared-aperture UHF/ UWB RFID reader antenna of circular polarization," IEEE Transactions on Antennas and Propagation, vol. 66, no. 8, pp. 3886-3893, 2018.

[11] W. Sun, Y. Li, Z. Zhang, and Z. Feng, "Broadband and lowprofile microstrip antenna using strip-slot hybrid structure," IEEE Antennas and Wireless Propagation Letters, vol. 16, pp. 3118-3121, 2017.

[12] K. M. Luk, Y. X. Guo, K. F. Lee, and Y. L. Chow, "L-probe proximity fed U-slot patch antenna," Electronics Letters, vol. 34, no. 19, pp. 1806-1807, 1998.

[13] S. Liao, Q. Xue, and J. Xu, "Parallel-plate transmission line and L-plate feeding differentially driven $\mathrm{H}$-slot patch antenna," IEEE Antennas and Wireless Propagation Letters, vol. 11, pp. 640-644, 2012.

[14] N.-W. Liu, L. Zhu, W.-W. Choi, and J.-D. Zhang, "A lowprofile differentially fed microstrip patch antenna with broad impedance bandwidth under triple-mode resonance," IEEE Antennas and Wireless Propagation Letters, vol. 17, no. 8, pp. 1478-1482, 2018.

[15] B. Huang, M. Li, J. Huang et al., "A compact shared-aperture hybrid-mode antenna for sub-6G communication," in Proceedings of the 2019 International Conference on Microwave and Millimeter Wave Technology (ICMMT), Guangzhou, China, May 2019.

[16] R. Li, G. DeJean, J. Laskar, and M. M. Tentzeris, "Investigation of circularly polarized loop antennas with a parasitic element for bandwidth enhancement," IEEE Transactions on Antennas and Propagation, vol. 53, pp. 3930-3939, 2005.

[17] B. Huang, W. Lin, J. Huang, J. Zhang, G. Zhang, and F. Wu, "A patch/dipole hybrid-mode antenna for sub- $6 \mathrm{GHz}$ communication," Sensors, vol. 19, no. 6, p. 1358, 2019.
[18] K.-S. Chin, W. Jiang, W. Che, C.-C. Chang, and H. Jin, "Wideband LTCC $60 \mathrm{GHz}$ antenna array with a dual-resonant slot and patch structure," IEEE Transactions on Antennas and Propagation, vol. 62, no. 1, pp. 174-182, 2014.

[19] S.-W. Qu, J.-L. Li, and Q. Xue, "Bowtie dipole antenna with wide beamwidth for base station application," IEEE Antennas and Wireless Propagation Letters, vol. 6, pp. 293-295, 2007.

[20] S. R. Best, "Improving the performance properties of a dipole element closely spaced to a PEC ground plane," IEEE Antennas and Wireless Propagation Letters, vol. 3, pp. 359-363, 2004.

[21] H. Huang, Y. Liu, and S. Gong, "A broadband dual-polarized base station antenna with sturdy construction," IEEE Antennas and Wireless Propagation Letters, vol. 16, pp. 665-668, 2017.

[22] N.-W. Liu, L. Zhu, W.-W. Choi, and X. Zhang, "A low-profile aperture-coupled microstrip antenna with enhanced bandwidth under dual resonance," IEEE Transactions on Antennas and Propagation, vol. 65, no. 3, pp. 1055-1062, 2017.

[23] I. Tzanidis, Y. Li, G. Xu, J.-Y. Seol, and J. Zhang, "2D active antenna array design for FD-MIMO system and antenna virtualization techniques," International Journal of Antennas and Propagation, vol. 2015, Article ID 873530, 9 pages, 2015. 